005.32:331.101.32

\title{
The Impact of Trust on Job Performance in Organisations
}

DOI: 10.7595/management.fon.2016.0028

\begin{abstract}
In circumstances governed by consistent change in all aspects of business, trust represents a significant factor in the behavioural patterns of organisations. Of great importance for a successful communication in organisations is understanding the levels of trust among staff, employees and their management, and trust in the organisation itself. Trust is a cohesive and motivating factor in work groups. Also, based on trust are identification and commitment to the organisation, as well as the relationships of employees. In successful organisations special attention is given to the problems of trust and mistrust. This work considers different theoretical concepts of how trust is created and maintained in organisations, different dimensions of organisational trust, as well as the effects of trust in organisational performance.
\end{abstract}

Keywords: trust, organisation, employees, managers, business

\section{Introduction}

The demands which contemporary organisations set before their employees have also initiated an increased commitment to people and their individual characteristics, among which trust occupies the most significant position.

The problem of trust in organisational relations opens up numerous questions, such as: what it is the quickest way to establish trust, does trust depend on the characteristics of employees, does it depend on the structure and culture of the organisation, in which mechanisms is trust best maintained among staff and within the organisation itself, how do management styles affect the establishment of trust, can trust contribute to an increase in business results, as well as others - numerous questions to which great attention is dedicated in developed countries. Organisation and management questions which require answers: in what way is organisational trust established, is it created based on managerial control, incentives, inspirational management or internal individual motivation? The preconditions for the development of trust, according to most authors who have studied trust, are the following: previous communication experiences as part of work behaviour, the existence and ways of using social connections and contacts, intentions behind activities and the similarities which exist in these engagements. The paper examines the concept of trust from the position of job performance, which can be influenced by trust issues. The consequence behind the existence of trust in interpersonal communication is often reflected in the reduction of risk perception, as well as in the cost reduction of joint endeavors. The benefits for all communication among participants based on trust are reflected in the cohesion in joint activities, reduction of potential opportunistic activities, reduction in formal contact use, increased reliability in creating business results, the predictability and openness in communication, as well as an increase in efficiency (Steppänen et al., 2007). The starting point for the analysis of organisational trust in our work is to consider the trust as part of the internal relations between employees, not as personal characteristics and beliefs.

\section{A theoretical Approach to Trust}

Trust has become an important research topic in various disciplines, including management, ethics, sociology, psychology and economics. Even though this multi-disciplinary approach has opened numerous theoretical access points (Rousseau et al., 1998), it has also created confusion in defining and conceptualizing 
the very construct of trust. One group of theories consider trust to be instinctive, to evolve from the readiness to divide food in hunter-gatherer societies (Nooteboom, 2003). Other groups of theories maintain that people have a need for trust out of fear of punishment if they are unable to perform what is expected from them, in order to achieve their own individual goals; in order to demonstrate empathy, identification and friendship; or simply, because they want to trust (Reynolds, 1997). Some theoreticians view trust as a behavioural intention (Mayer et al., 1995; Rousseau et al., 1998), while others describe it as a communication determined by choice (Lewis and Weigert, 1985). A third group of theoreticians see trust as a synonym for one's individual characteristics complemented by positive expectations from other individuals (Butler and Cantrell, 1984). Some view trust as an aspect of personality which develops in an early period of development and remains relatively stable throughout life (Rotter, 1967). Finally, there are those theoreticians who treat trust as a synonym for cooperation and risk-taking (Lewis and Weigert, 1985) but also often as an operationalization of behaviour in communities (Deutsch, 1958). In contemporary settings, studies of everyday human interaction have defined trust as a significant factor in maintaining social processes.

From the approach and aspects of rational choice, trust is interpreted as a rational perception in which the benefits of trust will be greater than the risk that exists when efforts are invested in cooperation (Hindmoor, 1998; Warren, 1999). Williamson even considers trust itself to represent a certain dose of risk (Williamson, 1993). In fact, trust represents much more than a rational calculation of the individual because it is frequently based on commitment, even beliefs, with the presence of the emotional component, sometimes even a religious one, as well as with expectations that other individuals will treat us in the same way in which we treat others (Newman, 1998; Misztal, 1996; Warren, 1999). Trust represents a system of shared expectations, but is also a phenomenon which implies that every participant within the interaction is given a sense of certainty. The sense of certainty is provided by the fact that there exists a possibility to predict the future behaviour of the other party, to count on it and to trust it.

Understanding trust implies the differentiation between two fundamental components of trust: readiness to react in situations of vulnerability and risk (Mayer et al., 1995) and reassurance guided by positive expectations (Lewicki et al., 1998; Mayer et al., 1995).

Trust is defined as the readiness of one party to accept the actions of the other party based on expectations that the other party will complete a specific task important for them, without the possibility of controlling their work (Mayer et al., 1995). As Zaheer and his associates (Zaheer et al., 1998) claim, trust represents an individual tendency to believe in something you have determined on your own. Trust also implies a reciprocal belief in the intentions and behaviour of others (Kreitner and Kinicki, 1998), a dependable reliance in the integrity, honesty, fairness and trustworthiness of others (Funk and Wagnalls, 1985), as well as a representation of an irrational choice of a person faced with uncertain events in which the expected loss is greater than the expected gain (Deutsch, 1958).

These definitions rely on a personal approach of the interpretation of trust in organisations. Since it was necessary to include the social environment in explanation of trust, Fukuyama defines trust, affected and shaped by a culture dominant in a society, as expectation of a regular, honest and cooperative behavioural patterns, believing that trust plays an important role in shaping economic performance of businesses and countries (Fukuyama, 1995), as well as a set of social expectations formed on the foundations of people, processes or institutions shared by all and which include an economic exchange (Zucker, 1986).

From the aspect of interpersonal relations it is possible to define trust as a mutual relationship in which neither party will hurt the other, or use each other's vulnerability (Barney and Hansen, 1994) and a belief which implies positive expectations about somebody else's motives in communication, even when they occur in precarious situations (Lewicki and Bunker, 1996);

Such a wide range of definitions, on the one hand, makes it easier to give a unique access and analysis, but, on the other, makes it more difficult. Meta-analysis indicates the importance of reciprocity in the given definitions of trust, or expectations of behaviour and intentions of others. Taking into account the explanations offered, we believe that those do not fully explain the phenomenon of trust. The question is what is the liable decision of the individual to communicate with other people based on trust, if only until the moment when trust is lost. 


\section{Organisational Trust}

In works on organisational behaviour one is able to find various definitions of trust, but all of them refer to similar characteristics of human behaviour. Trust is based on the observation of the other party in communication, via understanding the competence of the other party and their motives. The assessment of competence relates to a two-sided competence of both observer and the other party, through an observation of one's own abilities and the abilities of those with whom he cooperates, as a competence that both of them can accomplish what the situation requires. Observing the intentions and motives of individuals implies an overview of whether someone's words, decisions or actions are motivated by mutual usefulness, rather than motives of self-interest. Yamagashi (Yamagashi and Yamagashi, 1994) believes that organisations in which trust is fostered, are places where employees feel they have a better wellbeing than in other organisations, which is the starting premise in our perception of the role of trust in the organisation. The role of trust in organisational terms is not a one-dimensional phenomenon, and still depends on numerous factors. In that sense, Mishra believes there are four dimensions of organisational trust. Those are competence, openness and honesty, employee care and reliability (Mishra, 1996). New studies by Shockley and Zalabak, Ellis and Winograd, have discovered another important factor which needs to be taken into consideration, as do the four previously mentioned, and that is identification (Shockley-Zalabak et al., 2000) which measures the level of attitude we have towards common goals, norms, values and beliefs, combined with the organisational culture. This dimension indicates how our feelings are connected to our management and associates.

In order to explain trust within an organisation Eberl used the game theory and the theory of attribution, describing trust as a fundamental relational phenomenon, regardless of whether it is between individuals or organisations. Eberl makes a difference between trust that refers to the relative one-sided presumption of competence and the perception that the other party will not act opportunistically. The attribution processes shows whether or not the relationships based on trust will form. From the perspective of organizers, trust is especially relevant as a moderator that alleviates coordination (Eberl, 2004).

The famous thought experiment known as the "prisoner's dilemma" explains, through the principles of game theory and in an interesting way, the access to trust and the development of it. Two men arrested, separated at hearings, receive an identical offer. If they both choose the option to fully trust each other and do not admit anything, they both receive a minimum sentence. A selfish behaviour and shifting the blame to another prisoner leads to release, while if they both choose this approach they get a heavy penalty each. It logically follows that both prisoners will tend to show untrustworthy and selfish behaviour, because whatever one party decides, the other one will pass without maximum penalties. However, if the prisoners play cooperatively and help each other with silence, they both receive a minimum sentence.

Transferred to the field of organisation, cooperative behaviour based on trust will give better results and favourable outcomes for all parties.

Lewicki and Bunker consider three phases in the development of trust in organisations: trust based on finance, trust based on knowledge and trust based on positive identification. They point out that the three phases of trust are connected in sequential development; they are not three separate types of trust. In circumstances where people are convinced their interests are protected, trust is developed. An increased identification allows employees to think like others and to develop a collective identity, common goals and common values. In that model, trust develops and changes over time (Lewicki et al., 2006).

In order to further clarify the subject numerous models of trust development are conceived. Mayer's model of trust development represents an integrative model of organisational trust, respecting the characteristics of the person who gives trust, then the person to whom trust is given and the role of risk in the establishment of trust in communication.

The model of trust by Donnie and Cannon represents an integrated theory of several theoretical approaches and demands the assessment of the other party's validity and benevolence. In the model, they study the characteristics of those who receive trust and those who give their trust. Three factors contribute to an individual's tendency to consider the trustworthiness of the other person, and those are the abilities based on compensation in order to secure what the trustee expects; then, the integrity based on facts that the other person is led by principles accepted by the person who gives their trust; and third, the benevolent behav- 
iour associated with the intentions of the person who places their trust that the other person will do the best in his ability for the person that places his trust in them.

The model of trust development by Sheppard and Sherman (Sheppard and Sherman, 1998) indicates that trust is created depending on the specifics of the social context in which communication takes place, and is based on the overview of the context for the establishment of trust within that specific context. For trust to be established in a business context, it is necessary to observe the history of reliability of the other party, their attitude towards deceit, altruism, benevolence and care for others, which make up the desired characteristics for trust building.

Nor do even numerous models of the building of trust respond to concerns related to the phenomenon of trust in organisations. One additional reason is that in the studies indicators of negative connections between trust and organisational performances are found. For example, the Langred study (2004) reveals how, in teams with high levels of individual autonomy, high levels of trust can lead to decreased effects in team performance, rather than in teams with low levels of autonomy and high levels of control. In their study Wintrobe and Breton (Wintrobe and Breton, 1986) argument that in conditions where conflict exists in vertical lines of communication between employees and colleagues and their management, trust at horizontal lines of communication is reduced.

Impersonal organisational trust relates to trust in organisational factors such as vision and strategy, top management, goals and abilities, technological and commercial abilities, fairness, fair processes and structures, roles, technologies and reputation, and the function of human resource management (McKnight et al., 1998; Kramer, 1999; Tan and Tan, 2000). In organisation theory, the organisational culture in the sense of values, norms and identities influences the impersonal nature of organisational trust. Multi-disciplinary studies with an emphasis on organisational trust have identified vision, strategy, decision-making processes, roles and managerial practice of human resources, as sources of impersonal elements of trust.

The culture of the organisation, as a possible motivator and indicator of organisational behaviour, is a common indicator of effectiveness of organisational performance. The answer to the question of the relations between cultural characteristics and trust is given in the work by Yamagishi and associates (Yamagishi and Yamagishi, 1994), whose careful examination of trust in Japan and the United States of America refutes the common idea that trust is high in Japan and low in the United States. Their study examines how social culture affects organisational trust, with special interest in the question of what is the difference between trust in organisations found in collectivistic and that found in individualistic cultures. They differentiated trust between an individual level - a tendency to believe, and at an organisational level - part of internal relations among employees.

In works about organisational behaviour there is consent that trust is an important factor in managerial processes. According to Carnevale and Wechesler (Carnevale and Wechesler, 1992), trust provides the foundation for security and reliability in the intentions and actions of the supposed parties. This idea is reflected in numerous theoretical examinations of trust and its effect on business attitudes, behaviour, activities and performances. Dirks and Ferrin (Dirks and Ferrin, 2001) see trust as a result of effects such as positive attitudes, higher levels of cooperation and other behaviour which contributes to positive business results of an organisation. In order to understand trust in organisations it is necessary to view various dimensions of trust, social circumstances governing the establishment of trust, organisational foundations for trust and personal dispositions that govern the development of trust.

Research in organisations has shown that the perception of trust must combine both approaches to trust, the organisational and the individual approaches. When it comes to mutual trust, it is of essential importance to define the reality of the relationship of mutual trust based on characteristics of the organisation and personal characteristics of employees (Krasman, 2013). In the context of the organisation, trust is considered one of the crucial elements of organisational effectiveness. It can be seen as a cohesive force which maintains relations within the organisation (Whitney, 1994). Without trust people would not be able to work together, unless found in a controlling environment. The significance of trust grows to a large extent due to the effects trust has on forms of communication and the effectiveness of job completion, likewise in a reversed order. For example, when there exists a gap in trust among employees and their managers, chances that the observed manager is seen as the source of information are greatly lessened. Lately, trust is considered 
the key to communication forms and the processing of information in an organisational context, to a large extent due to its influence on communication (Zeffane, 2006). It is clear that trust in management can affect the course of information flow as well as the perception of clarity and preciseness of information. Adequate explanations and timely feedback are largely connected with the levels of trust, as are accurate and future communication.

Numerous authors regard the relation between trust and task completion, expressed in most studies, as a cause; again, there are authors who regard the relationship as even stronger than the relationship of trust and attitudes towards other aspects of work, such as, for example, job satisfaction (Judge et al., 2001). Trust is also a significant aspect in risk-taking, which is of vital importance in numerous jobs where formal or legal control is not able to create desired results (Hardin, 1991). In addition, trust positively correlates with effective commitment, through which the influence of work motivation is viewed (Meyer et al., 2002). Trust improves team work, leadership, goal setting and performance assessment (Jones and George, 1998; Mayer et al., 1995; McAllister, 1995) and contributes to satisfaction among employees and their dedication to organisation (Flaherty, 1999).

\section{Conslusion}

Trust in relationships among employees in organisations is an important factor in the realization of organisational performance. However, it has been established in the majority of case studies that trust is built as the result of three factors which encourage trust: communication, collective problem-solving, and fairness in reward, as well as two factors which undermine it: conflict and egocentricity. Bstieler argued that trust facilitates relations which precede trust, as well as performances which affect organisational behaviour (Bstieler, 2006). Studies on the development of trust have shown that individuals observe the reliability in others and express a willingness to engage in interaction with them, primarily as result of previous experiences in communication (Solomon, 1960). For example, several studies have shown that the reciprocity in relationships increases trust, while the lack or violation of exchange undermines it (Deutsch, 1958). Interestingly, certain studies have also concluded that there are negative effects of high levels of trust in interpersonal relations, contributing to dysfunctional achievements in situations when there exists an over-reliance on certain people (Molina-Morales et al., 2011).

Distrust and doubt are often the problems in many organisations. Distrust is defined as the absence of trust in others, a concern that people might act in a harmful and hostile way towards other people. Organisational trust is more than the accumulation of individual trust at a determined level of relation. From the perspective of the organisation, it is possible to view trust through the dimensions of ability, benevolence, and honesty as the foundations of organisational behaviour. For the relation of employees towards both work and the organisation, institutionally based trust, which is the core of intraand inter-organisational trust since it spans beyond interpersonal relations, is the result of organisational identification with certain values and social practices, such as tradition, profession and written procedures. Organisations with high levels of trust have a tendency to create products and services with less cost, because they employ highly motivated, risk-taking, innovative individuals who can easily accept the vision, mission and values of the organisation (Galford and Drapeau, 2002). In terms of accelerating business changes, narrowed professional specialization, as well as in terms of the quantity of job requirements, work in organisations requires the establishment of trust among employees. The significance of trust for an organisation is in the improvement of business results, while to the individual it gives safety and acceptance within the collective group. 


\section{REFERENCES:}

[1] Barney, J. and Hansen, M. (1994). Trustworthiness as a source of competitive advantage. Strategic Management Journal, 15, 175-90.

[2] Bstieler, L. (2006). Trust formation in collaborative new product development. The Journal of Product Innovation Management, 23, 56-72.

[3] Butler, J. K., Jr. and Cantrell, R. S. (1984). A behavioural decision theory approach to modeling dyadic trust in superiors and subordinates. Psychological Reports, 55, 19-28.

[4] Carnevale, D. G. and Weschler, B. (1992). Trust in the public sector: individual and organisational determimans. Administration and Society, 23 (4), 471-494.

[5] Deutsch, M. (1958). Trust and suspicion. Journal of Conflict Resolution, 2, 265-279.

[6] Dirks, K. T. and Ferrin, T. L. (2001). The role of trust in organisational settings. Organisation science: A journal of the Intitute of Management Sciences, 12 (4), 450-467.

[7] Eberl, P. (2004). The Development of trust and implications for organisational design: A game- and attribution-theoretical framework. Schmalenbach Business Review, 56, 258 - 273.

[8] Flaherty, K. (1999). The role of trust in salesperson-sales manager relationships. In: Gordon, P.J. and Kellerman, B.J. (Eds.), Proceedings of the American Marketing Association Summer Educators' Conference. American Marketing Association, Chicago, p. 58.

[9] Funk and Wagnalls. (1985). Standard Desk Dictionary. Harper and Row.

[10] Fukuyama, F. (1995). Trust: The Social Virtues and the Creation of Prosperity. New York: The Free Press.

[11] Galford, R. and Drapeau, S. A. (2002). The Trusted Leader: bringing out the Best in your People and Your Company. The Free Press.

[12] Hardin, R. (1991). Trusting persons, trusting institutions. In: Zeckhauser, R. (Ed.), Strategy and Choice. Cambridge: MIT Press, p. 185-209.

[13] Hindmoor, A. (1998). The importance of being trusted: Transaction costs and policy network theory. Public Administration, 76, 25-43.

[14] Jones, G. R. and George, J. M. (1998). The experience and evolution of trust: implications for cooperation and teamwork. The Academy of Management Review, 23 (3), 531-536.

[15] Judge, T. A., Thoresen, C. J., Bono, J. E., \& Patton, G. K. (2001). The job satisfaction-job performance relationship: A qualitative and quantitative review. Psychological Bulletin, 127, 376-407.

[16] Krasman, J. (2013). Do my staff trust me? The influence of organisational structure on subordinate perceptions of supervisor trustworthiness. Influence of organisational structure, 35 (5), 470-488.

[17] Kramer, R. M. (1999). Trust and distrust in organisations: emerging perspectives, enduring questions. Annual Review of Psychology, 50, 569-598.

[18] Kreitner, R. and Kinicki, A. (1998). Organisational behaviour (4th ed.). Itwin Mc Graw-Hill.

[19] Lewicki, R., McAllister, D. J. and Bies, R. J. (1998). Trust and distrust: new relationships and realities. Academy of Management Review, 23 (3), 438-458.

[20] Lewicki, R. J. and Bunker, B. B. (1996). Developing and maintaining trust in work relationships. In: Kramer, R. M. and Tyler, T. R. (Eds.) Trust in Organisations: Frontiers of Theory \& Research. Thousand Oaks: Sage Publications.

[21] Lewicki, R., Tomlinson, E. C. and Gillespie, N. (2006). Models of interpersonal trust development: theoretical approaches, empirical evidence, and future directions. Journal of Management, 32 (6), 9911022.

[22] Lewis, D. and Weigert, A. (1985). Trust as a Social Reality. Social Forces 63 (4): 967-985.

[23] Mayer, R. C., Davis, J. H. and Schoorman, F. D. (1995). An integrative model of organisational trust. Academy of Management Rewiev, 20 (3), 709-734.

[24] McAllister, D. J. (1995). Affect and cognition-based trust as foundations for interpersonal co-operation in organisations. Academy of Management Journal, 38 (1), 24-59.

[25] McKnight, H., Cummings, N. and Chervany, L. (1998). Initial trust formation in new organisational relationships. Academy Management Review, 23 (3), 473-490.

[26] Meyer, J. P., Stanley, D. J., Herscovitch, L. and Topolnytsky, L. (2002). Affective, continuance and normative commitment to the organisation: A meta-analysis of antecedents, correlates and consequences. Journal of Vocational Behaviour, 61, 20-52.

[27] Mishra, A. K. (1996). Organisational responses to crisis: The centrality of trust. In: R. M. Kramer \& T. R. Tyler (Eds.). Trust in Organisations: Frontiers of Theory and Research, pp. 261-287. Thousand Oaks, CA: Sage.

[28] Misztal, B. (1996). Trust in Modern Societies. Cambridge: Polity Press. 
[29] Molina-Morales, X., Martinez-Fernandez, T. and Torlo, J. (2011). The Dark Side of Trust: The Benefits, Costs and Optimal Levels of Trust for Innovation Performance. Long Range Planing, 44 (2), 118-133.

[30] Newman, J. (1998). The dynamics of trust. In: Coulson A. (Ed.), Trust and contracts: Relationships in local government, health and public services. Bristol: The Polity Press.

[31] Nooteboom, B. (2003). The Trust Process. In: Nooteboom, B. and Six, F. (Eds.) The Trust Process in Organisations: Empirical studies of the Determinants and the process of Trust development. Edward Elgar Publishing Inc.

[32] Reynolds, L. (1997). The Trust Effect: Creating the High Trust, High Performance Organisation. Nicholas Bradley Publishers.

[33] Rotter, J. B. (1967). A new scale for the measurement of interpersonal trust. Journal of Personality, 35, 651-665.

[34] Rousseau, D. M., Sitkin, S.B., Burt, R.S. and Camerer, C. (1998). Not so different after all: A crooss-discipline wiev of trust. Academy of Management Reviw, 23 (3), 393-405.

[35] Sheppard, B. and Sherman, D. (1998). The Grammars of Trust: A Model and General Implications. The Academy of Management Review, 23 (3), 422-437.

[36] Shockley-Zalabak, P. Ellis, K.Winograd, G. (2000). Organisational trust: What it means, why it matters. Organisation Development Journal, 18 (4), 35-48.

[37] Solomon, L. (1960). The influence of some types of power relationships and game strategies upon the development of interpersonal trust. Journal of Abnormal and Social Psychology, 61 (2), 223-230.

[38] Steppänen, R., Blomqvist, K. and Sundqvist, S. (2007). Measuring inter-organisational trust - a critical review of the empirical research in 1990-2003. Industrial Marketing Management, 36, 249-265.

[39] Tan, H. H. and Tan, C. S. F. (2000). Toward the differentiation of trust in supervisor and trust in organisation. Genetic, Social and General Psychology Monographs, 126, 241-260.

[40] Warren, M. E. (1999). Democratic theory and trust. In: Warren M. E. (Ed.), Democracy and trust. Cambridge: Cambridge University Press.

[41] Whitney, J.O. (1994). The Trust Factor. New Jork: McGraw-Hill.

[42] Williamson, O. E. (1993). Calculativeness, trust, and economic organisation. Journal of Law and Economics, 34, 453-502.

[43] Wintrobe, R. and Breton, A. (1986). Organisational structure and productivity. American Economic Review, 76, 530-538.

[44] Yamagishi, T. and Yamagishi, M. (1994). Trust and commitment in the United States and Japan. Motivation and Emotion, 18 (2), 129-66.

[45] Zaheer, A., McEvily, B. and Perrone, V. (1998). Does trust matter? Exploring the Effects of inter-organisational and interpersonal trust on performance. Organisation Science, 9 (2), 141-159.

[46] Zeffane, R. (2006). Factors affecting prrefered sources of information: Exploring the impact of trust, job satisfaction and communication effectivness. Management, 11 (2), 93-110.

[47] Zucker, L. G. (1986). Production of Trust: Institutional Sources of Economic Structure, 1840-1920. Research in Organisational Behaviour, 8, 53-111. 


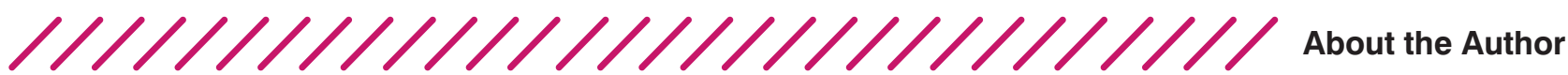

\section{Ana Nešić \\ University of Novi Sad, Faculty of Technical Sciences}

Ana Nešić earned her PhD degree at the University of Novi Sad, Faculty of Philosophy, Department of Sociology. Also, she is a PhD candidate at the Faculty of Technical Sciences, Department of Industrial Engineering and Management, Module of Human Resource Management. She is the author of numerous scientific papers and she has successfully undertaken various team projects, within both academic and non-academic environments.

\section{Danijela Lalić \\ University of Novi Sad, Faculty of Technical Sciences}

Danijela Lalić, Ph.D., is an associate professor at the Department of Industrial Engineering and Management, Faculty of Technical Sciences, University of Novi Sad. She teaches undergraduate and graduate courses, both academic and professional (MBA). Her research interests include public relations (corporate communication) management, business communication, marketing, social media, and Internet communication. Danijela is especially interested in Internet and Intranet systems, networking, and new technology. She has uccessfully led a national scientific project and has participated in numerous international projects. Danijela spent over two years studying abroad, in Austria and Slovenia (where she completed her doctoral studies and thesis, at the University of Ljubljana, Faculty of Social Sciences).

She is the author of over 60 scientific and professional publications. Her PR handbook

("Examples of Good Practices in Public Relations," vols. 1-3) is widely considered an excellent guide for professionals and students who have an interest in communication. Danijela was an editor and lead translator of the textbook Business Communication Today, published by Pearson Education. Danijela is a founding partner of the ProMethod Network Solution System consulting agency, where she is involved in communication management and new media strategy

development projects. Through them she has cooperated with scientific institutions, public relations agencies and domestic and international companies. Danijela contributes to the development of her profession by an active participation in the Serbian Public Relations Association. She is the president of the jury for national competitions and a past member of the board of managers. 